\title{
Using Co-Design to Express Cultural Values and Create a Graphical Identity: A Case Study of Khon Kaen, Thailand
}

\author{
Ratanachote Thienmongkol
}

\begin{abstract}
This paper outlines one of the significant design processes in my practice based design project. It involved creating a new design of the public transport map (BRT Khon Kaen) for Khon Kaen city. Collaborative and participatory design concepts are presented in this paper. Both concepts can be used to present the voice of stakeholders within the community who played a central role in my design process. It can be noted that democracy design can be used with the heuristic concept of graphic designers to reach a design solution. The human factors that formed the knowledge base of the community were critical to providing the challenging ideas that created the identity sets of map symbols on my design prototype (map). The graphic details on the map features display the design materials which related to the local ways of life, folk wisdom, and culture. This design contribution expressed the cultural values and created a consistency between map readers and their background knowledge. The results of my usability test found that graphical materials, which relate to user's backgrounds, can be used to enhance communication and recognition.
\end{abstract}

Index Terms-Co-design, graphic design, community participation, transit map.

\section{BACKGROUND}

In the next few years, Khon Kaen city will reform the Urban Transport System (UTS) introducing a new project 'Bus Rapid Transit' (BRT) that will replace the old local transport 'SongThel' (Mini-Bus). This project will affect the areas of Khon Kaen municipality. The project will create radical change by replacing the whole operating system of public transport. This plan has also included research regarding new routes, architecture and corporate identity designs, which were created as the design prototypes. These design artifacts were defined by following the key concepts of 'Sin-Chai' literature that is the major concept of urban and people development policies of the Khon Kaen municipality [1].

However, even though Khon Kaen is situated in the areas of the 'Lan Chang' empire ${ }^{1}$ and the Sin-Chai has been a traditional literature for the 'Mekong River' of more than 900 years, the Khon Kaen community does not have any relationship to the literature in terms of history, geography and the calendar [2]. The learning experience of people in the

Manuscript received June 1, 2014; revised August 2, 2014.

Ratanachote Thienmongkol is with the New Media Department, Faculty of Informatics Mahasarakham University, 44000, Thailand (e-mail: ratanachote.t@gmail.com).

${ }^{1}$ In 1869-2321BC, the 'Lan Chang Empire' covered the areas of the Mekong Riverbank across Laos and Northeast Thailand (Isan region), some parts of Cambodia and Vietnam; and the bottom areas of the South of China [1]. community in the twentieth/twenty first century has not meant a familiarity and consistency with the Sin-Chai literature. The authors considered that Sin-Chai literature has not been strong enough to provide the key images and identity designs for Khon Kaen city and the new UTS. Further details of this argument are addressed in topic five.

This point challenges me, in the role of Khon Kaen people, a user, a researcher and a graphic designer, to question "how can I research the real "local identity" from the knowledge base of stakeholders in the community (Human Factors)?” and "how can I transform this knowledge into the form of graphic materials on the BRT transit map?” I believe that the co-design approach can create identity designs in public spaces based on the democratic responsiveness, community ownership and respect of culture values.

\section{The CASE Study Context/Culture}

Khon Kaen province is located in the center of the Northeast region in Thailand, better known as the 'Isan' region. Khon Kaen province has the fourth largest population of Thai cities, at 1.76 million people, while the CBD contains 250,000 people. Its geographical location and development policies have made Khon Kaen a center of business, education, medical professions, and transport in the region. Local government is the Khon Kaen municipality (or Khon Kaen City Council).

Isan culture represents all traditional practices in the Isan region, covering the ways of life in this area [3]. An Isan style has a strong identity derived from foods, languages (accents), eating, folk arts, customs, amusements and beliefs. Khon Kaen is one of 19 provinces in the region, which preserves Isan traditionalism. Although the Isan region shares common traditional practices, each province has their own strong folk wisdoms [4]. For example, in 'Yasothon' province there is a Fireworks festival; 'Ubonratchathani' province has the Beeswax-Candle festival, and 'Nong-Khai' province has the Long-Boat competition. Meanwhile, Khon Kaen has the Silk festival. The silk-cloth (Par-Mai) products are world famous goods, and represent the folk wisdoms in this province (see the examples in Fig. 1) [5].
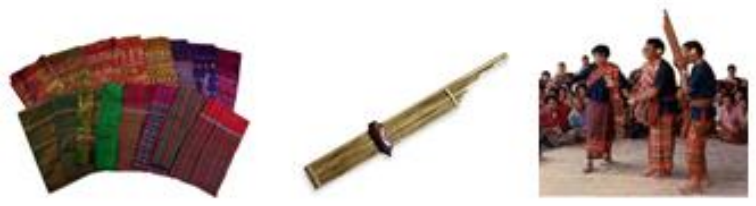

Fig. 1. These pictures present the tradition of Khon Kaen folk wisdom, folk musical instrument and custom: (left) Silk Cloths, (centre) Khaen and (right) Isan country folk music. 
The Bamboo Mouth Organ (called 'Khaen') is a key musical instrument for the Isan country-folk music (called 'Mor-Lum') Hence, different folk wisdom in each province has been built up contribute to local images and identities (see Fig. 2).
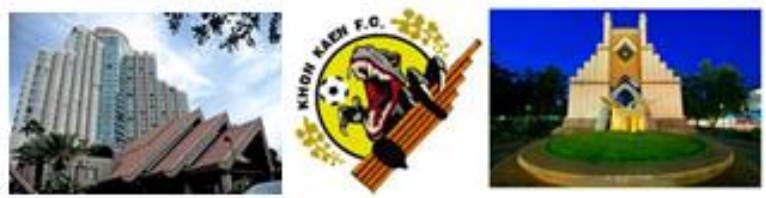

Fig. 2. These pictures depict Khaen as the famous representing symbol in Khon Kaen city: (left) a Khaen with the hotel building design, (centre) a Khaen with logo and (c) aKhaen with the city clock tower.

\section{The New Role And New System Impact With the CiTY IMAGE}

In 2015 the Southeast of Asia Nations or 'ASEAN' will associate as the 'Asean Economics Community' (AEC). The AEC consists of 10 member countries ${ }^{2}$ in this community system [6]. Since 1982 Khon Kaen province has been promoted by the central government to be one of five major cities in Thailand [7]. This promotion meant Khon Kaen has to make adaptations in the logistics and transport hubs in the Isan region, in order to support the aim of 'East West Economic Corridor' (EWEC) of the AEC.

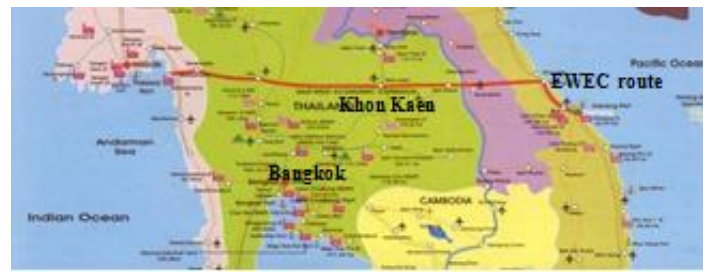

Fig. 3. This map show the location of Khon Kaen province at the center of the Isan region. This area is the heart for distribution of goods to Indo-China.

EWEC will consist of double lines of trains and motorways from Burma to Thailand, through Laos and stopping in Vietnam [8]. Fig. 3 shows that Khon Kaen city is located at the center of the Isan region and Indo China areas (Indo-China areas consists of Cambodia, Laos, Thailand and Vietnam [9]). Any goods, cargo or transit passengers need to be stored and stay in the city before distribution. These reasons prompted Khon Kaen municipality to introduce the new public transport plan (under the name of "Khon Kaen BRT") ${ }^{3}$. This plan will also support a transit commuter (e.g. people, investors, and tourists) system, and reform their urban transport system.

The BRT project was collaboratively planned between Khon Kaen municipality and Khon Kaen University. In the years 2009-10, the BRT master plan involved: 1) cancellation of the old mini-bus system and installation of the new BRT;2) creating the new network route service; 3 ) adapting city land use planning; and 4) defining new interchange stations, stops,

\footnotetext{
${ }^{2}$ The AEC consists of Indonesia, Malaysia, Philippines, Singapore, Thailand, Brunei, Burma, Cambodia, Laos and Vietnam [10].

${ }^{3}$ Bus Rapid Transits (BRT) are transit systems that will use buses to provide a faster service for commuting passengers in the special (bus) lanes [11]
}

fare systems, and timetables. Lynch [12] argued that the changing of the urban transport project would have a significant impact in modeling the image of cities. Hence the development of a graphic support system that could be applied to assist people to recognize and use their urban space [13]. The reformation of a public transport system needs to create a new user information system, including a transit map, map handout, graphics on the buses, tickets, graphic material in the stations, bus shelter and bus stop. The Khon Kaen BRT project is not only reforming the operating system, but it will also modify the city image by using the Environmental Graphic Design (EGD) approach. It will become an opportunity to see Khon Kaen city's fast transformations and the changing image of the city.

\section{THE EGD EXPERIENCE WITH URBAN TRANSPORT SYSTEM IN THE CITY}

Gibson [14] explained that the EGD is related to an organization of the spatial space in urban areas, signage systems, and public design systems of wayfinding applications for creating an appropriate message to communicate with people. Cohesive information and a unifying visual element in a graphic communication system, for a given location in a built environment, is key to the systematic development in the EGD spectrum activity [15].

Although Khon Kaen city provides a mini-bus system (20 lines), there is no public transit information to show people how to use it. Even the large transit nodes in Khon Kaen city provide no graphic material of user information guidelines (e.g. wayfinding of minibus with map, timetable, and fare rates). This is evidenced in Fig. 4. The new arrival of the BRT system will not only reform the UTS, but will bring with it the new arrival of the EGD experience in UTS for the city and people [16].

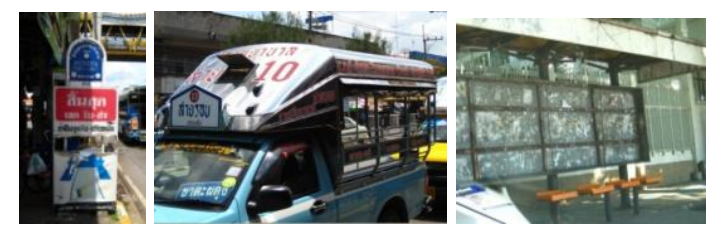

Fig. 4. These pictures show on overview of challenges in the largest transit nodes in the city: (left) an old information board (without updating) is the concealed by advertising canvas, (center) the Thai language around the minibus is the informal information that every buses for passenger, (right) the overview of bus stops in the city that is worn out and dirty.

\section{THE INFLUENCE OF THE LOCAL POLICY REFLECTS TO THE CITY IMAGE}

With the new EGD experience, Khon Kaen municipality awakened to the need to define the corporate identity for the BRT system. Since 2007 “Nakhon Pang-Jan" (Pang-Jan City) is the key aspect/identity that some local administrators believe the city image should look like (key finding from in-depth interview). This city is the name of the city in the 'Chadok Tale'. Sin-Chai literature is one part of the stories

\footnotetext{
4 'Chadok' is the stories of the Lord Buddha's former births. Most of Chadok in Thailand would like to present just the last 10 worlds from 1,000 of the Lord Buddha's world ('world' means the cycle of birth and death).
} 
in the Chadok Tales, which are concerned with Pang-Jan city ${ }^{5}$.
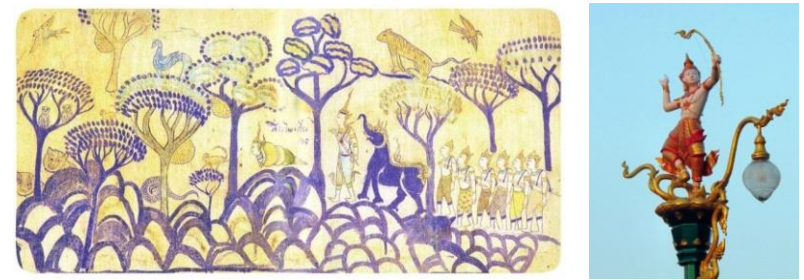

Fig. 5. These pictures present the transforming idea from Sin-Chai mural painting to a design of electricity poles installed around the downtown areas.

Nowadays, Sin-Chai is a famous and valuable literature in the Isan region. Two of the temples in Khon Kaen province have mural art related to Sin-Chai literature [17]. This prospect made Khon Kaen municipality use Sin-Chai as the key design strategy in developing their urban policy [18]. For example, in terms of the urban development policy (2010-12), Sin-Chai acted as the mascot and identity concepts of the city around the municipality areas (see pictures in Fig. 5) [1]. This concept was designed on the (bus) model in the BRT master plan project. Moreover, the five new transit routes were named using the name of heroes in the Sin-Chai story; though these characters are not related to the history of each area (see Fig. 6).
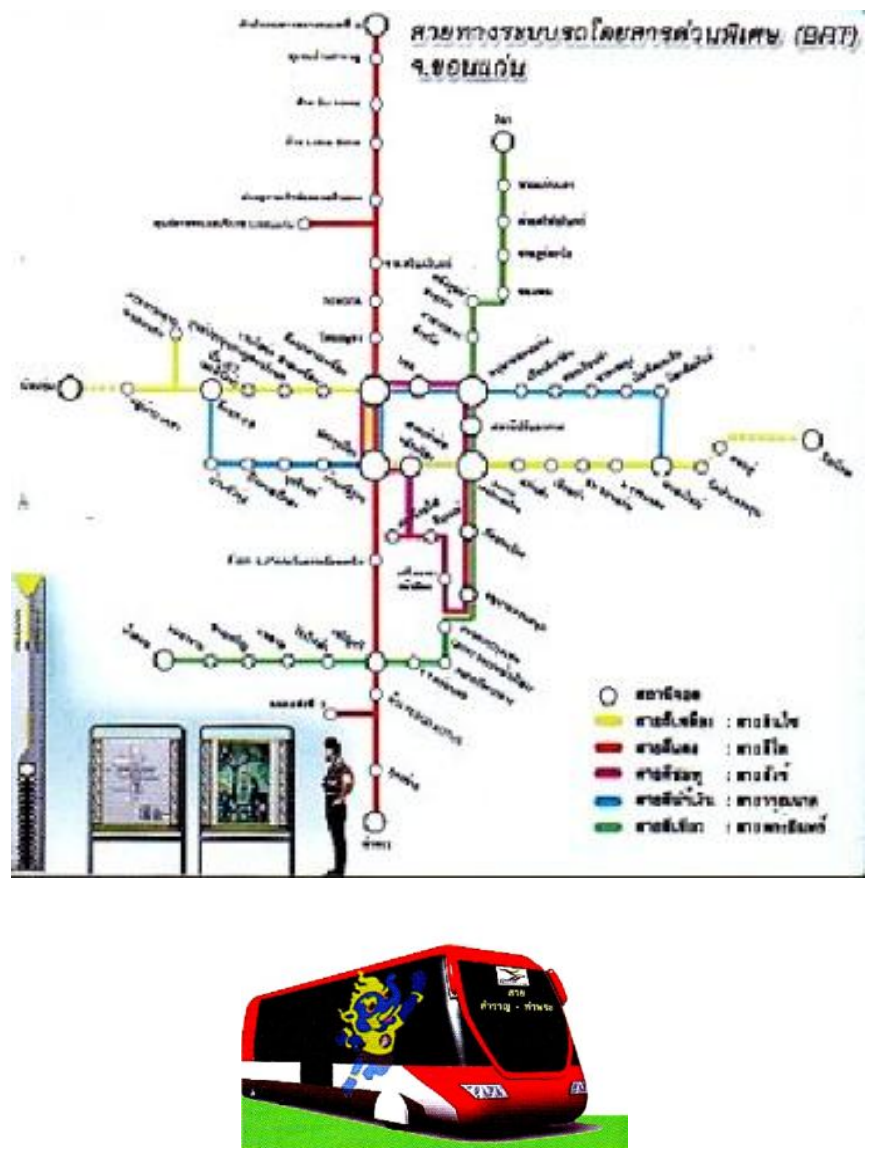

Fig. 6. These pictures present some of the corporate identity design of the BRT: (left) BRT routes (names in Thai), (right) the BRT logo with alphabet ' $\mathrm{K}$ ' design and one of the heroes in Sin Chai literature screened on a bus model.

${ }^{5}$ In Thai, Chadok tale explained that Sin-Chai is the King of Pang-Jan city [2].
In fact, the Pang-Jan city and Sin-Chai story are directly related to the historical geography, site and monuments in the Nong-Khai province. Around 1200BC, Pang-Jan city was established by local people in the 'Ratanawape district' (Nong-Khai province); most people believed that Sin-Chai used to be the king of this ancient city [2]. However, Khon Kaen province has no relationship with either story. These traditional paintings were painted by local artists around Isan region such as Mahasarakham, Karasin and Roi-Et provinces [17]. From these inconsistencies with Khon Kaen's history, I believe that Sin-Chai literature has not been strong enough to represent the city and new BRT identity designs. Local government used a traditional top-down policy to create the city image without the citizens' participation.

\section{Applying Co-Design to the Design Project}

The critical review of the current background of Khon Kaen's identity design concept, made the authors question whether the Sin-Chai concept was the best way to contribute to the local identity design concept. This section presents an alternative method to inquire about the key human factors from the stakeholders in Khon Kaen city (knowledge base of community). The co-design was utilized as the core design concept in my design process in order to allow stakeholder participation in the design method.

Billington [19] stated that a co-design concept came from the American pragmatist tradition. He contended that grass-roots democracy is based on the rights and freedoms locals have to participate. Creighton [20] supported the notion that citizen participation has a broad value to community life because of 1) engages the public, 2) builds trust, and 3) makes better decisions for the community. Sanders and Dandavate [21] and Sanoff [22] stated that in many cases, using citizen experiences can enhance the chance of success compares with simply using outside professionals. This is because citizens are more realistic regarding the local contexts.

In the early 1970s-1980s, the participatory design (or cooperative) concept developed in the Scandinavian computer professional system [23], [24]. This concept rapidly expanded to other fields such as; interactive, industrial, information and graphic design areas [25]. Visser et al. [26] explained that design cannot be separated from society; everybody uses design as part of their daily lives. This means a designer has to be responsible to the people in what and how they design. However, the principles of participatory design methods, tools and techniques are dependent on the type of organization, technology, and number of people involved with the project [27]. Schuler and Namioka [28] suggested that a participatory design will require testing existing products or prototype of developed concepts by users, in order to ensure that those users' and other stakeholders' knowledge will be utilized in the design process, and the design of products will fit their lives. However, the co-design concept prompted me to think about which group of people would be involved and dealing with my design project. The co-design concept also gave me ideas for selecting methods and research instruments appropriate for my data collection and analysis. Details are described in 
the next topics.

\section{THE RESEARCH PARTICIPANTS}

I used a stakeholder mapping technique to determine the main strategy for recruiting potential research participants, and who would be involved with the process of data collection. This concept further extended my understanding of the different perspectives, views, relationships and roles of people in the Khon Kaen community [29]. Stakeholder mapping is a method commonly used by applying the table of two variables [30], as seen in Fig. 7. One (left) side of the square represents the 'power/influence' level of people in Khon Kaen city, who are involved with the decision making in terms of an administration system. Meanwhile, the (top) side represents the 'importance' level of people in the city, who are involved with the outcome of my designs.

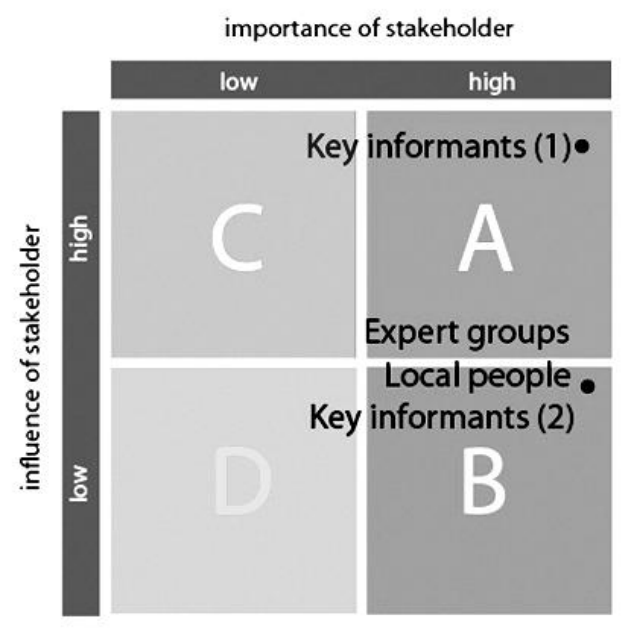

Fig. 7. This table presents the stakeholder matrix and the positions of my main sample groups.

The author categorized the main group of participants, who would be the representatives of Khon Kaen stakeholders, as follows: 1) local people, 2) experts, and 3) key informants which consists of two sub-groups (a) local administration groups and (b) community users/drivers of local transportation. These groups were placed in different positions on the stakeholder matrix. The detail of participant groups is provided in Table I.

TABLE I: THE ARRANGEMENT OF CHANNELS

\begin{tabular}{l}
\hline \hline $\boldsymbol{B O X} \boldsymbol{A}$ : are people, who have high-influence and high-importance \\
in the community and BRT project. This is the Key Informants \\
group 'A', consists of five heads of local administration; \\
(1) Mayor/Khon Kaen Municipality, (2) Head Officer/Khon Kaen \\
Transport Center, (3) Head Officer/Khon Kaen Tourism Center, (4) \\
Head Officer/City sport and Tourism, (5) Chairman of City Economic \\
Chamber \\
\hline \hline BOX $\boldsymbol{B}$ : are people, who have high-importance but low-influence in \\
the community and the BRT project. It consists of three groups; \\
Local people (130 people, Male/Female): the group of local people \\
such as: (1) people with disabilities, (2) elderly persons, (3) students, (4) \\
workers, (5) business people, (6) high/low incomes people, (7) monks \\
Key Informants Group B (2 people): (1) a passenger (representative 1 \\
female), (2) a Song-Theal driver (representative 1 male) \\
Expert groups (3 people): (1) Transport engineering field (1 academic), \\
(2) Urban design field (1 academic), (3) Isan folk art and Isan culture \\
fields (1 academic)
\end{tabular}

\section{MiXED-Methods ApPROACH}

The research used a mixed-methods approach, with both quantitative and qualitative methods. Because I dealt with large and small groups of people in the community, I needed to combine several approaches, for example: deductive (quantitative) and inductive (qualitative) processes to investigate key variables (see the mixed-methods process in Fig. 8).

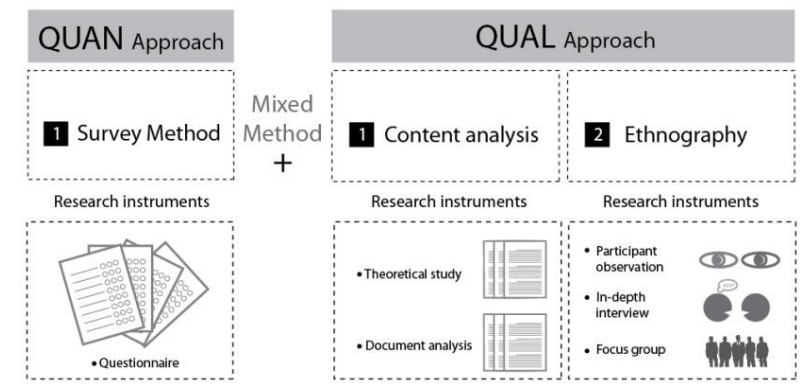

Fig. 8. Mixed-method approach for data collection: the methodologies used are shown and the research instrument within each methodology described.

\section{A. Research Tools and Task Description}

Questionnaire: I used a 'questionnaire' as the main instrument to survey the sample group of target populations. The questionnaire will be a deductive process. The interview technique was provided because some groups of participants may not read, or may have disabilities. I applied descriptive research methodology as the main approach to design my questionnaires. At the first phase, I piloted questions, choice of answer formats and technical devices. In the second phase, I used 'random selection' to choose a purposive sample. The results from the experimental group are not included in the process of data analysis.

Document Analysis \& Theoretical Study: In my theoretical study, I classified the two main contents about the theory of 1) urban transportation systems and 2) design theory (Co-Design, Semiotic thinking, infoDesign, design elements, typographic design, HCD, etc.). Documentary analysis used to identify the context of transport, transit behaviour and culture, and transit structures. It also included development plans and policy documents, which relate to the context of transport development in Khon Kaen city.

Participant Observation: I used field-note techniques to record observed, and apply autoethnography to record the researcher perspective (designer voice), which I obtain from reflections in the site work. These processes presented the transparent relationship between the researcher and my field work. My recording devices were a digital camera and voice recorder.

In-depth Interview: I applied a semi-structured format which included closed (structured) and open-ended (unstructured) questions. I used unstructured questions to define the framework of questions, creating a relaxing atmosphere during the interview process. The sample group of my in-depth interview include 1) the key informants in group A and group B, and 2) the expert groups. The snowball technique may be required if one of the key informants recommends another person as being helpful.

Focus Group: My focus group process defined the 
usability concept as the main theme of discussions. Sub-themes included; 1) usability, 2) desirability and 3) functionality [31]. My focus group set up in the form of discussions and workshops. I used questionnaires, note discussion ideas, and screened (classify) the group of participants as part of data collection. I used the overhead projector for presenting the design works, real-design prototypes and voice recorders.

\section{B. Research (Design) Methods}

The stages of my research method, including techniques of data collection and analysis, are presented in Fig. 9.
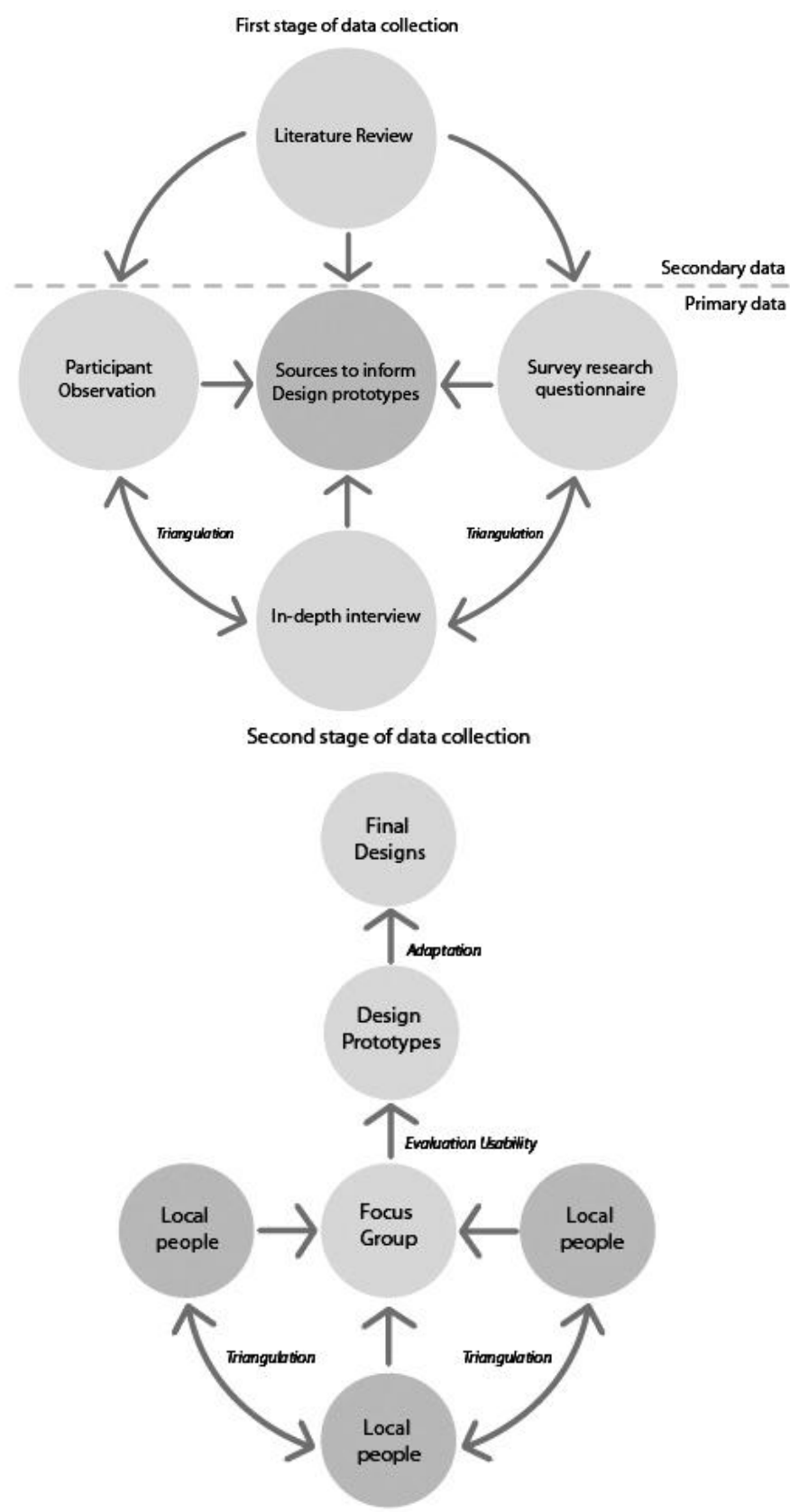

Fig. 9. These diagrams present the two major processes and elements of my research method.

This figure shows the relationship between the methods, techniques and steps of my research operation. The top side explains the first stage of the design method before designing the first prototype. The bottom side describes the second stage that is concerned with the usability test (design evaluation) concept. Feedback in this stage was brought to adapting the design prototype before creating the final design of Khon Kaen BRT transit map.

\section{Collecting AND Analytic Strategies}

A mixture of collection strategies, between sequential and parallel systems, was required during the process of data collection [32], which was divided into three steps (see diagram in Appendix A). Significant findings related to a main (BRT map) design concept are presented in each stage of data collection. The key findings were argued and contributed to ideas for designing my transit map prototype in the next section.

Stage 1: Data collection began using content analysis to review research documents (e.g. city, transport, policy, and culture contexts). Theoretical studies were also included in this process (e.g. information design, human-centred design, usability design, design elements and semiotics).

Analysis: I used content analysis to classify the type of information based on inference techniques made by systematically and objectively identifying specified characteristics of my research framework [33]. In terms of systematic analysis, I defined the information content as two main categories consisting of 1) document analysis and 2) theoretical study. In the document analysis, I regarded the main research questions [34], in order to classify key themes, terminology, and previous studies before reviewing key literature. Document sources included websites, newspapers, policy, textbooks and journals. Much of the content analysis in this part was conducted using inductive rather than deductive (objective) processes. In the theoretical study, I applied the same criterion used in the document analysis. Nevertheless, I analysed the context of my natural research framework, in order to understand the key related theory. Multiple data sources and collecting techniques were used in order to strengthen reliability, as well as internal validity, for data interpretation [35]. Appendix B presents a schematic draft of my content analysis process.

Stage 2: Parallel data collection using qualitative and quantitative approaches were applied in field work. This consisted of survey questionnaires (step1-prior study with 50 people, and step2- with 130 local people); observation and in-depth interview with the key informant group "A" (local administration groups) and group " $\mathrm{B}$ " (community users/drivers of local transportation).

Analysis: Key variables from the sampling were triangulated to credibility and internal validity. These key variables were classified to a different domain ${ }^{6}$, which depended on the nature and relation of each variable. Each domain was analysed and confirmed to ensure the final inductive inferences (the human factors) of this stage reflected the multiple realities of community relationship. Finally, these human factors were combined with the secondary data, and create the key conceptual design for the second phase (see Appendix C for the analysis diagram). These key design concepts were organised and transformed to graphical material by applying design theories (e.g.

\footnotetext{
${ }^{6}$ Consisted of 1) local culture perspectives, 2) transit behaviours, and 3) transportation needs.
} 
information design, design elements, colours theory, grids system, and typographic design).

Stage 3: The qualitative approach employed a focus group as the main instrument to collect ideas from evaluation workshops (using questionnaires) and group discussions with 24 local (sample groups). The purpose of the focus group was to share ideas between participants. The group consisted of students, university students, adults, elders, and disabled, with equal gender split of male and female, in order to evaluate the usability of my design prototypes. The evaluation theme in the questionnaire covered eight sections; 1) BRT logo, 2) graphic routes, 3) graphic for fare-rate and timetable systems, 4) route-symbols information, 5) key legends, 6) service information table, 7) index symbols and 8) overall design materials on the map. Each section consisted of three criteria for evaluating; 1) comprehension and communication efficiency with the graphic materials, 2) visible efficiency, and 3) the attractiveness of design materials.

Analysis: I used triangulation analysis with factors such as gender, age, education and income of my participants, and collection techniques (interview/questionnaire and focus group/discussion). The concurrent triangulation strategy was applied to the data to compare the quantitative results with the qualitative findings. I used descriptive statistics to detect the frequency score values in each usability test variable within the 8 sections of the questionnaire (including the demographic section) to identify the central tendency score. These scores were presented as the typical value of number, percentage, mean (minimum and maximum) and standard deviation (SD). Recorded interviews were transcribed before unitising and categorising the raw data. This analysis process revealed a key recommendation, confirmed and supported with a statistical result.

These average ${ }^{7}$ results were indicated in the form of the typical value of number, percentage, mean (minimum /maximum) and standard deviation. Key recommendations from participants were combined with statistic results and summarised ${ }^{8}$. Results from the concurrent triangulation provided significant feedback (human factors) to adapt the graphic material on my design prototype and produce the final design. Appendix E presents the analysis diagram of the last stage in my analytical process.

\section{Key FindingS And Design Outcomes}

\section{A. The Results from Stage 1}

Key finding 1: from the documentary analysis I found the urban development policy about Sin-Chai literature was not consistent with the historical site, geography and calendar of Khon Kaen province.

\section{B. The Results from Stage 2}

Key finding 2: from the in-depth interview with the key informants group A (5 interviewees), 2 people associated the

\footnotetext{
${ }^{7}$ These averages were the indicator validating each design (material) section on the complete map design as meeting the user requirements.

${ }^{8}$ These keys were a comparison test to check alternative design solutions; ideas that came from the users (and users) needs.
}

emblem of Khon Kaen city with Sin-Chai. Other emblems such as the sticky rice bucket, city gate, and Khon Kaen Lake received support from 1 person each. With regard to 'local' culture, 3 participants thought the Sin-Chai mural painting was the key representation of local culture.

Key finding 3: the in-depth interview with key informant group B, revealed that 'Khane' was the emblem of the Khon Kaen city. Additionally, they said the tradition of Isan textiles was the prominent point of local culture that they wanted presented to a visitor.

Key finding 4: the suggestion from the expert group using in-depth interview techniques found that the emblem of each city was dependant on the slogan of each province. Most of the emblems are articulated with a local way of life and related to the Buddha life and stories.

Key finding 5: using frequency analysis, the results of the questionnaire by 130 respondents revealed that for question E1-4, 68.9\% of local people answered that 'Khane' was the key emblem of the city. Meanwhile, for the question E1-3, $68.9 \%$ selected Isan textile (Par-Mai) as the prominent point of local culture that should be presented to a visitor.

\section{Argument 1}

The triangulation of methods and sources from the key findings no. 1 - no. 5; can be synthesised as three main factors. Factor 1: Khon Kaen city does not have relevance to any historical site, geography and calendar of Sin-Chai history. Factor 2: most of local administrators preferred to set up Sin-Chai as the emblem of the city. Factor 3: local people have strongly contrasting ideas about the emblem and prominent points of local culture compared with the local administrator group. These factors confirmed that the 'Sin-Chai' concept has not received local recognition. The emblem and prominent point of Khon Kaen culture arose from traditional practices and folk wisdom as present in Fig. 1.

\section{Deign outcomes (Design Prototype)}

I transformed the knowledge base of local people, experts and the needs of local administrators to my design prototype (see examples in Fig. 10 and Fig. 11). Fig. 10 presents the design of BRT logo, based on the concept of 'Khane' and the new 5 routes of the BRT system. The colours on the logo reflect the arrangement of the route construction beginning with the red route and ending with the yellow route. I also addressed the needs of the local administrators by applying the Sin-Chai mural painting style to the map (in fare rates information). The pictographic of people was created based on a local artist style. Fig. 11 shows the design concept as applied to a basic pattern of traditional local-textiles (Par-Mai) to create the original graphic style for the Khon Kaen BRT map. The designing of Isan textile consisted of two pattern lines (the major and sub lines pattern). I found the logical link between Isan-textile design and the Khon Kaen UTS context. I applied this traditional knowledge to defining the concept of my transit map prototype. I substituted the BRT as the major pattern; because, the BRT will be the major transit system of the city. Meanwhile, the Mini-bus system was represented as the sub patterns; because, this mode will become the supporter of the BRT system. 

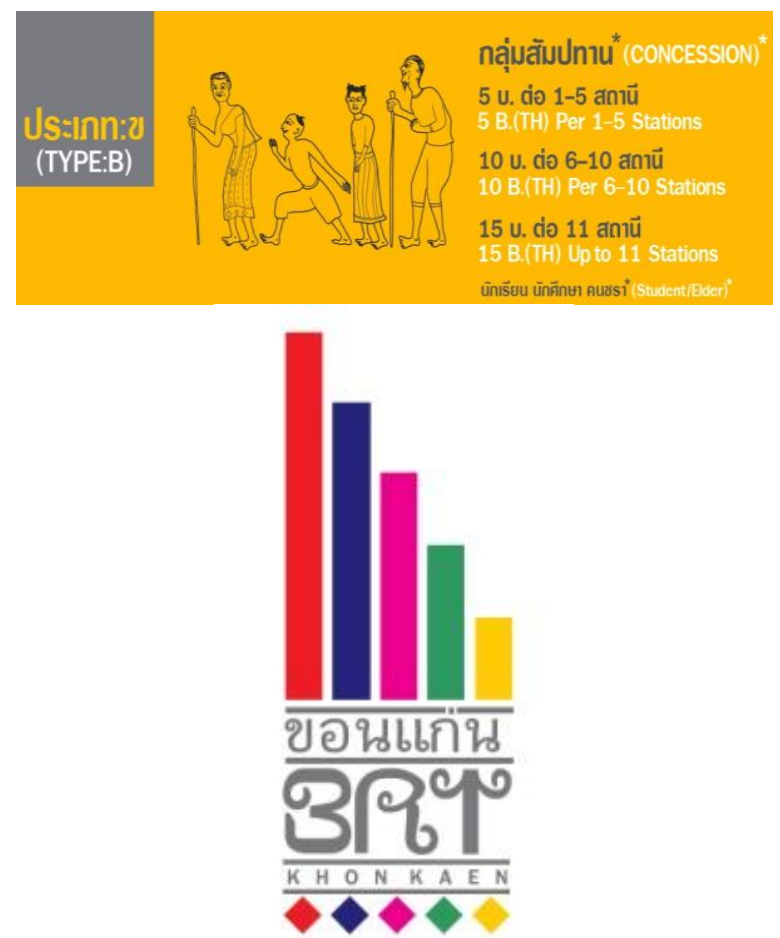

Fig. 10. These graphic present the outcome of design prototype: (top) some of the pictographic design on the fare rate system and (bottom) the logo.

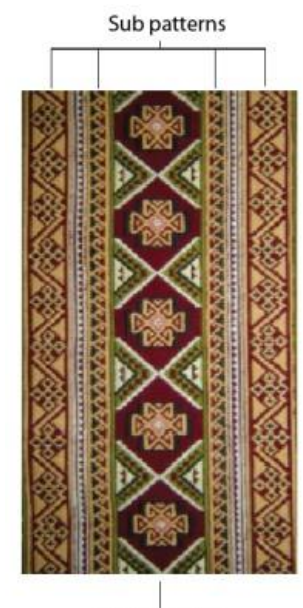

Major pattern

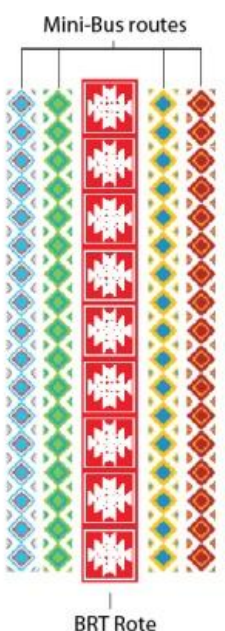

BRT Rote

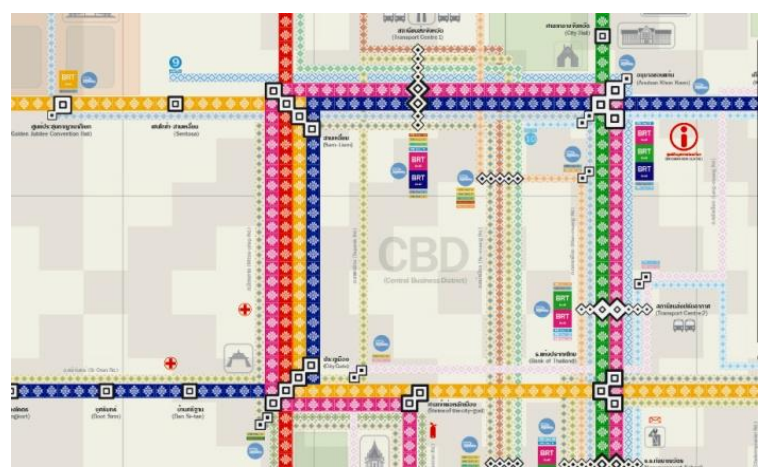

Fig. 11. These graphic present the experimental design concepts from a local textile concept to create the original design with graphic route on the map.

\section{E. The Results from Stage 3}

Key finding 6: results of descriptive analysis of the design scores of three criteria within the eight sections ranged from 3.7 points to 4 point (or $92.5 \%$ from 100\%) of "well designed" recognition. The sum of evaluating design scores are showed in Table II.
TABLE II: OVERVIEW OF DESIGN SCORES EVALUATED BY PARTICIPANTS IN THE FOCUS GROUP AND WORKSHOP DISCUSSION

\begin{tabular}{lllll}
\hline \hline \multicolumn{1}{c}{ Section } & N & min & max & mean \\
$\begin{array}{l}\text { 1. Sum design scores of BRT } \\
\text { logo }\end{array}$ & 24 & 2.66 & 4 & 3.58 \\
\hline $\begin{array}{l}\text { 2. Sum design score of graphic } \\
\text { design }\end{array}$ & 24 & 3.10 & 4 & 3.68 \\
\hline $\begin{array}{l}\text { 3. Sum design scores of graphic } \\
\text { fare-rate and timetable }\end{array}$ & 24 & 2.88 & 3.88 & 3.60 \\
\hline $\begin{array}{l}\text { 4. Sum design scores of } \\
\text { route-symbols information }\end{array}$ & 24 & 3.15 & 4 & 3.64 \\
\hline $\begin{array}{l}\text { 5. Sum design scores of key } \\
\text { legends }\end{array}$ & 24 & 3.28 & 3.96 & 3.78 \\
\hline $\begin{array}{l}\text { 6. Sum design scores of service } \\
\text { information tables }\end{array}$ & 24 & 3.16 & 4 & 3.65 \\
\hline $\begin{array}{l}\text { 7. Sum design scores of index } \\
\text { symbol designs }\end{array}$ & 24 & 2.85 & 3.96 & 3.70 \\
\hline $\begin{array}{l}\text { 8. Sum design scores of overall } \\
\text { design martrials }\end{array}$ & 24 & 3.33 & 4 & 3.82 \\
\hline $\begin{array}{l}\text { Sum design scores } \\
\text { Valid N (listwise) }\end{array}$ & 24 & 3.22 & 3.91 & 3.72 \\
\hline
\end{tabular}

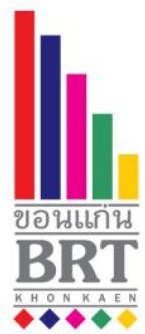

(a)

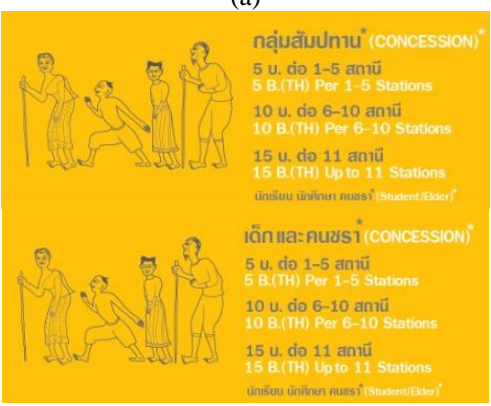

(b)

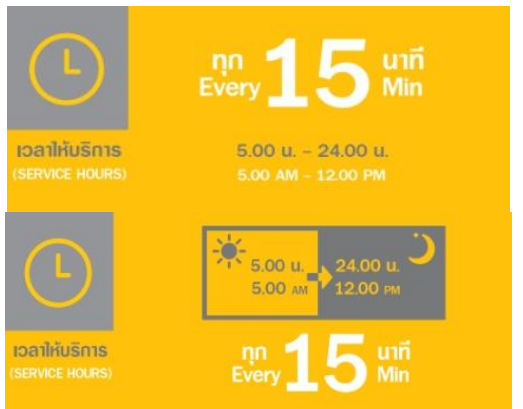

(c)
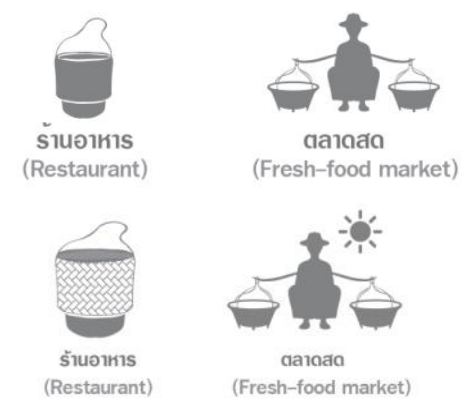

(d)

Fig. 12. These graphic some part of my adapted results: an idea came from the participant feedback and the usability test results from the focus group. 


\section{F. Argument 2}

Since 1970, the ISO defined the developing comprehension in public information design symbols under the code ISO7001 [36]. They suggested the testing level of public communication success should meet a figure of $67 \%$ comprehension of the control group with the symbol system. Hence, it can be stated that the sum design scores of this transit map have achieved the ISO7001 regulation. Table I represents the recognition of sample groups with my design prototype. The low point figures in the table section 1(2.66), $3(2.88)$ and $7(2.85)$ raised me awareness regarding which parts were unclear with graphical materials.

\section{G. Design Outcome (Final Design)}

In Section I, the adapting point was the typeface of 'BRT' on the logo. I applied a Thai alphabet to create a typographic character that looked like the English 'BRT' alphabet; however half the participants had difficulty with the spelling. At this point we cleared the typeface of the English alphabet and replaced the old font (see picture (a) in Fig. 12). In Section III we used of the word 'Concession' in Thai language "Sum-Pa-Tan" groups was found to be unclear for communication (in section of fare rates system). In particular the words to be replaced were "Dek-Ran-Kon-Cha-Ra" (students and elders) (see (b) in Fig. 12). In part of the time Table I adapted the timing icon (sun and moon) and colors to create fast recognition (see pictures (c) in Fig. 12). In Section VII I added more key visuals and details on the part of index symbols based on a participant comment (see picture (d) in Fig. 12). The Final design presents in appendix D.

\section{CONCLUSIONS}

This article has presented the body of knowledge with the participatory design in a community, map design, design methods, and the origin of design contribution. It has also considered using a democratic response, to local administration, to create a symbol of city identity. I believe that visual identity is not just about how the city looks; it is about how people look at your city. The design also presents the community response with respect to community ownership using local perspectives. Fig. 13, I propose the contribution of collaboration model for designing Khon Kaen urban transport map system. The model presents the participatory concept between the three major groups of stakeholder within the community. They can be able to share their individual perspectives, which come out in form of human factor needs (variables). A professional (or designers) is the person or team who integrate the needs of stakeholder basing on applying the principle of information design; in order to transform these needs (data) to a visual material. They also organize the evaluation process by using the usability test concept. This test is the usability guidance of ISO 9241-11, which ISO created to evaluate design products basing on the achievement area of effectiveness, efficiency and satisfaction in a specified context of use [31]. Moreover, a feedback from this evaluation can be able to enhance the learnability, memorability, and visual literacy of users, and also decrease the design errors [37].

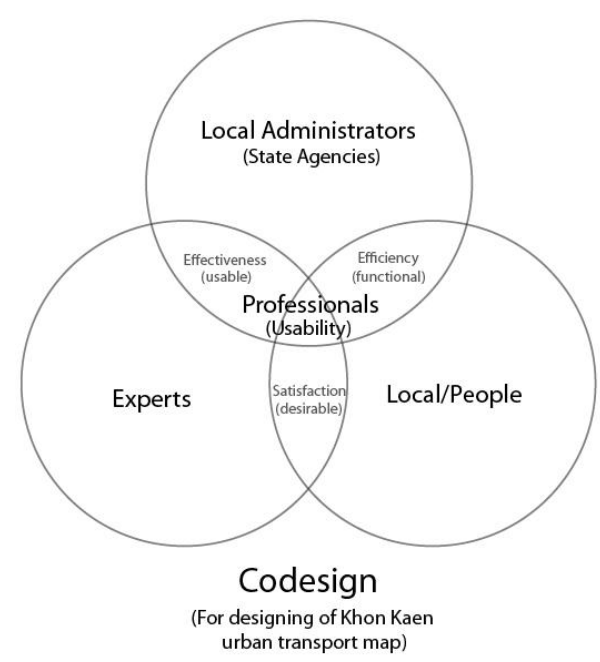

Fig. 13. These graphic some part of my adapted results: an idea came from the participant feedback and the usability test results from the focus group.

However, the top-down policy may work for other administrative proposes; this policy may distort the actual cultural values and the spirit of community folk wisdom. The key-findings confirmed the wrong direction of current urban image development policy in that the Sin-Chai concept is still far away from local minds. However, the co-design approach can be utilized to create collaborations between local stakeholders with the designer, and also empower people within the community to take ownership of design.

\section{ETHICAL CONSIDERATION}

Ethical approval was granted by the Auckland University of Technology Ethics Committee (AUTEC) and employed to guide my field work study. Information sheets were provided to participants in hard-copy and were communicated verbally for those who were illiterate. Consent forms were given to all interviewees to grant permission for their participation. Any transcribed material and data analysis was returned to participants involved with in-depth interviews. All participant names and contact details were made anonymous to protect their right to privacy.

\section{APPENDIX}

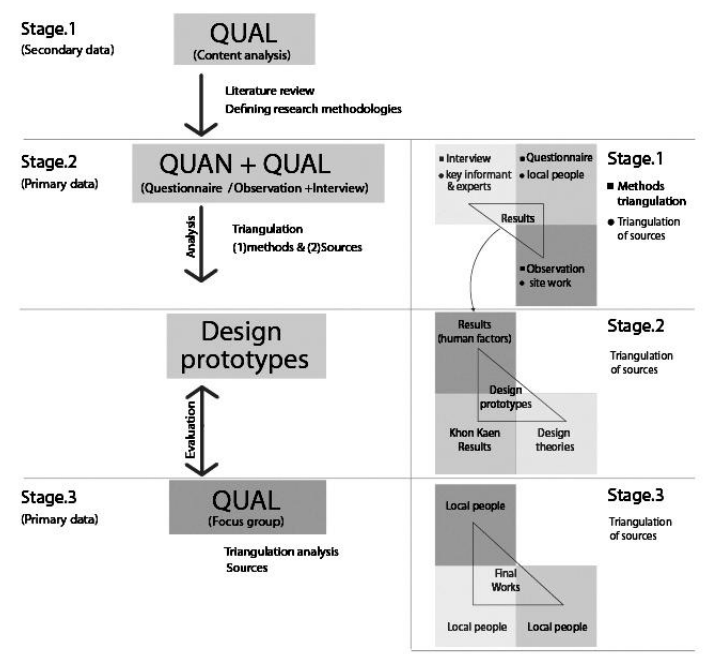


Appendix A. The example of typological analysis process in my content analysis method

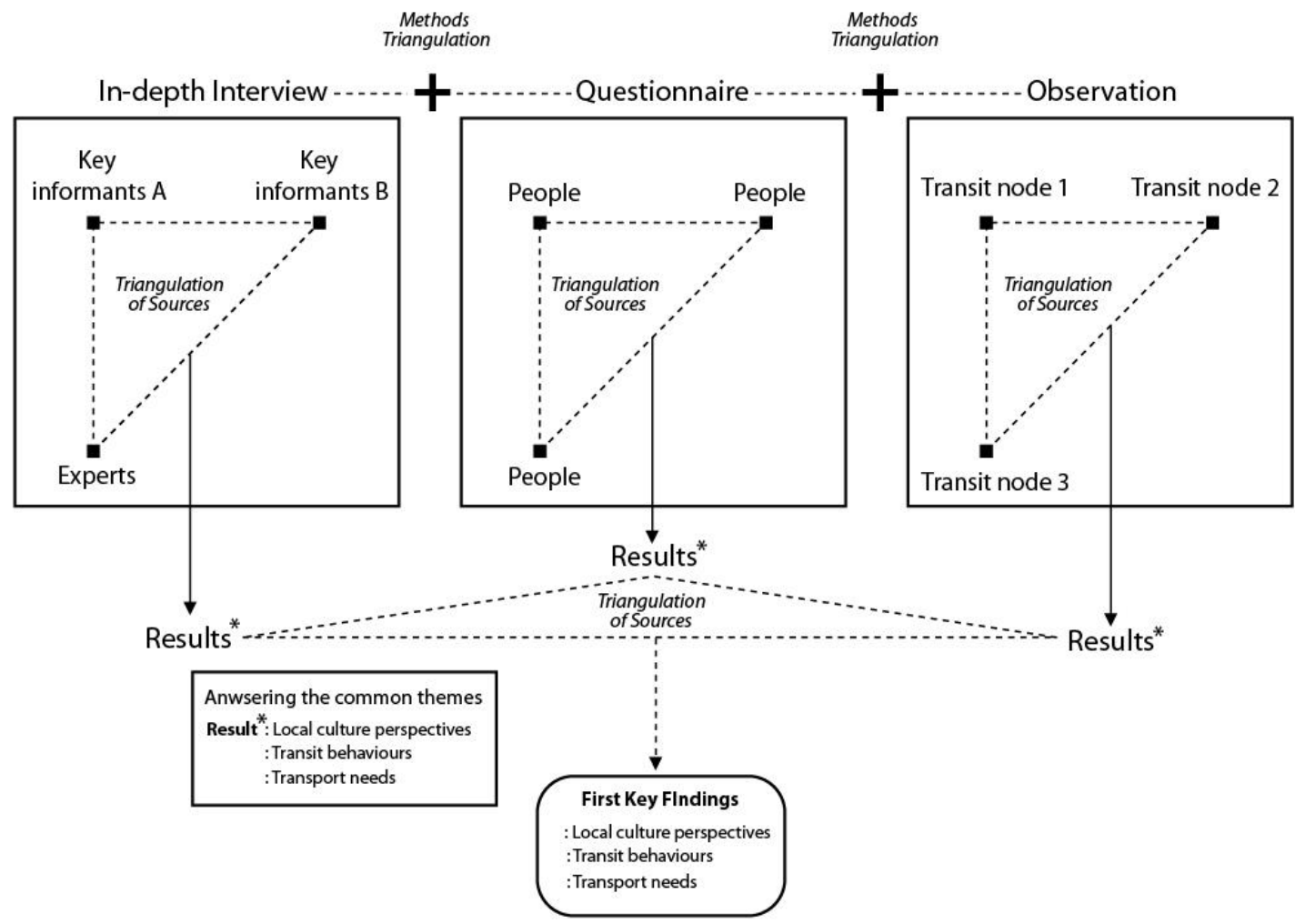

Appendix B. The relationship between the processes of data collection (left) and (right) data analysis strategies

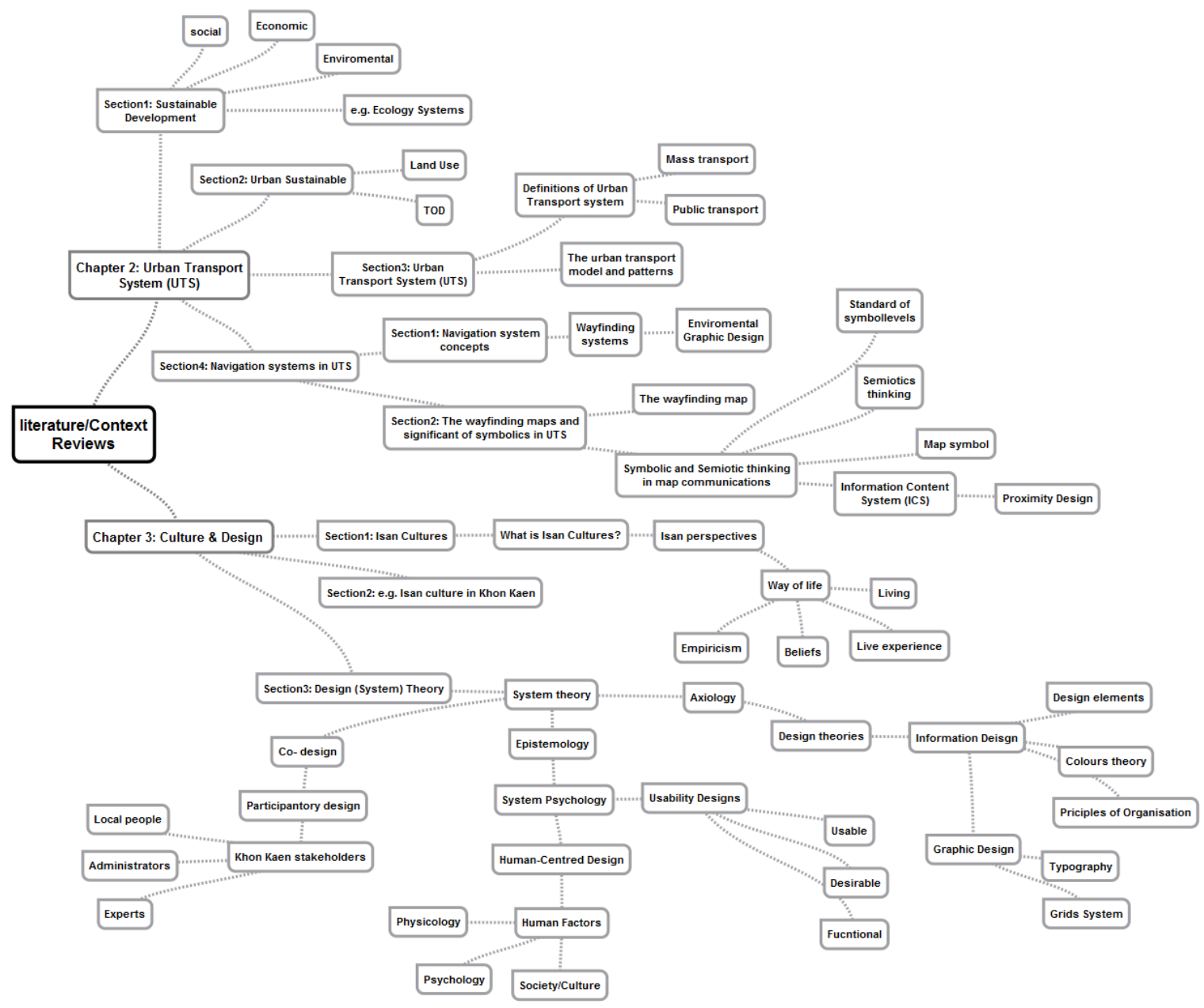


Appendix C. The outline diagram of my analytical data in the stage 2

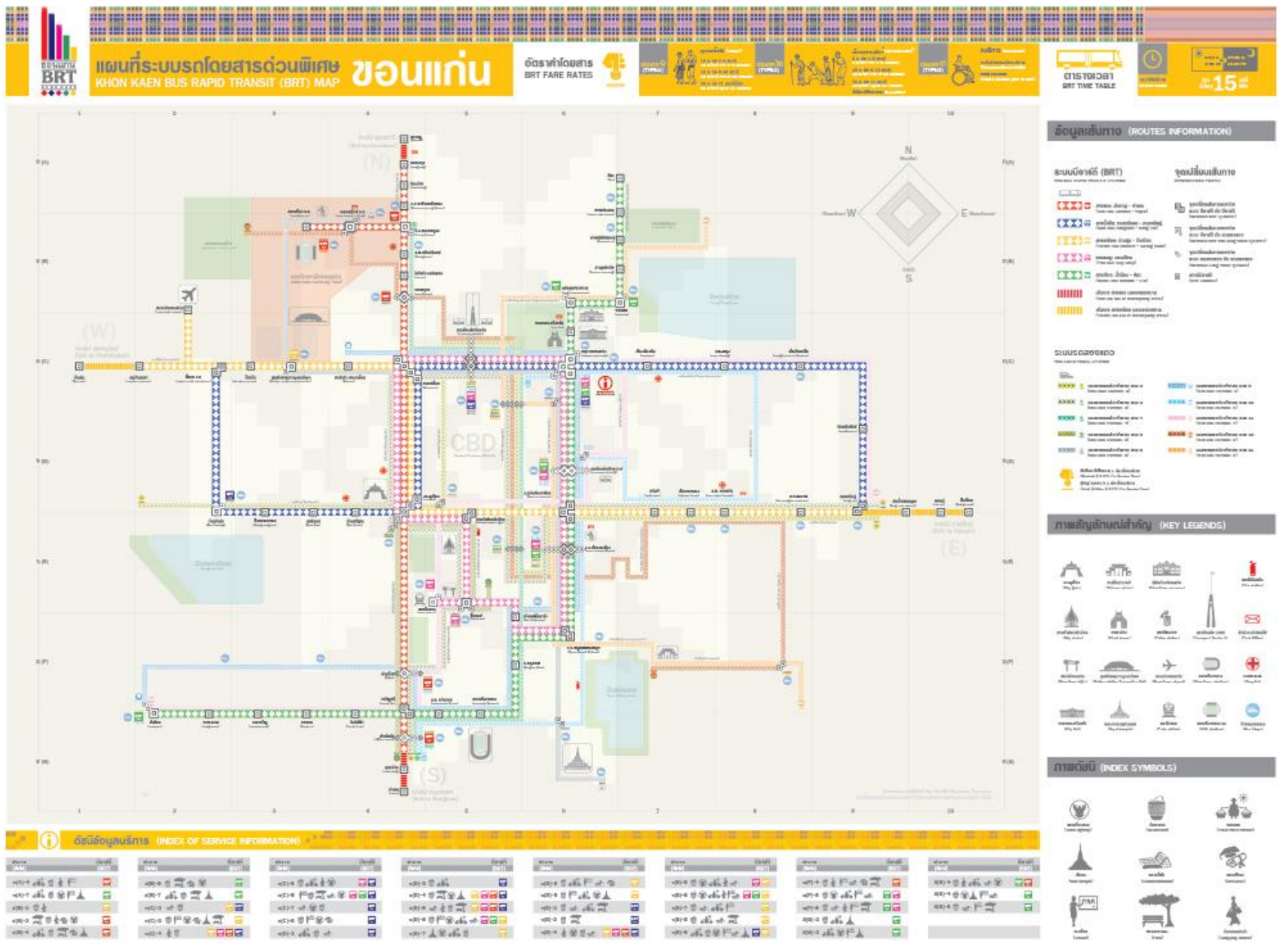

Appendix D. The final design after adapting the details from stakeholder feedbacks (see more detail in: http://visual.ly/khon-kaen-brt-map)

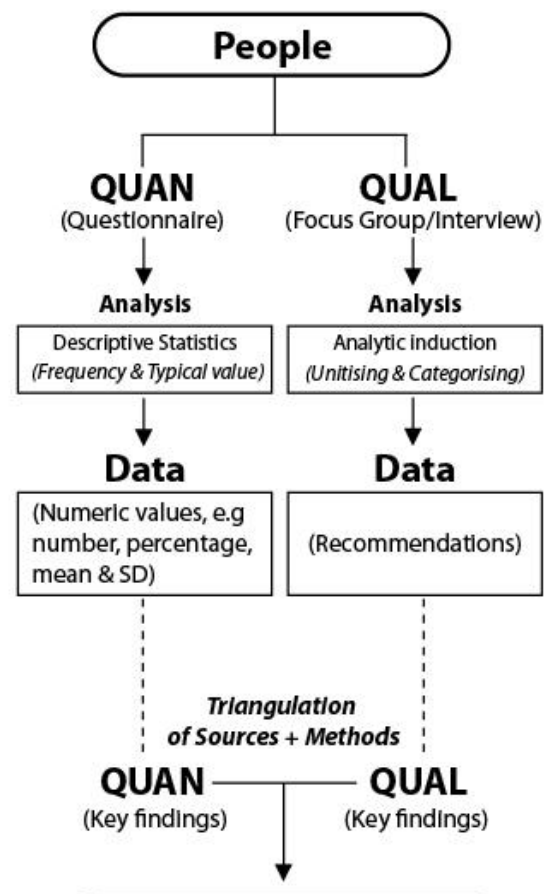

Final Feedbacks

(Usability + Human Factors) 
Appendix E. This diagram outlines of triangulation analysis in the focus group/workshop processes; in order to investigate usability test results and gather a feedback from the stakeholders, before created the final design

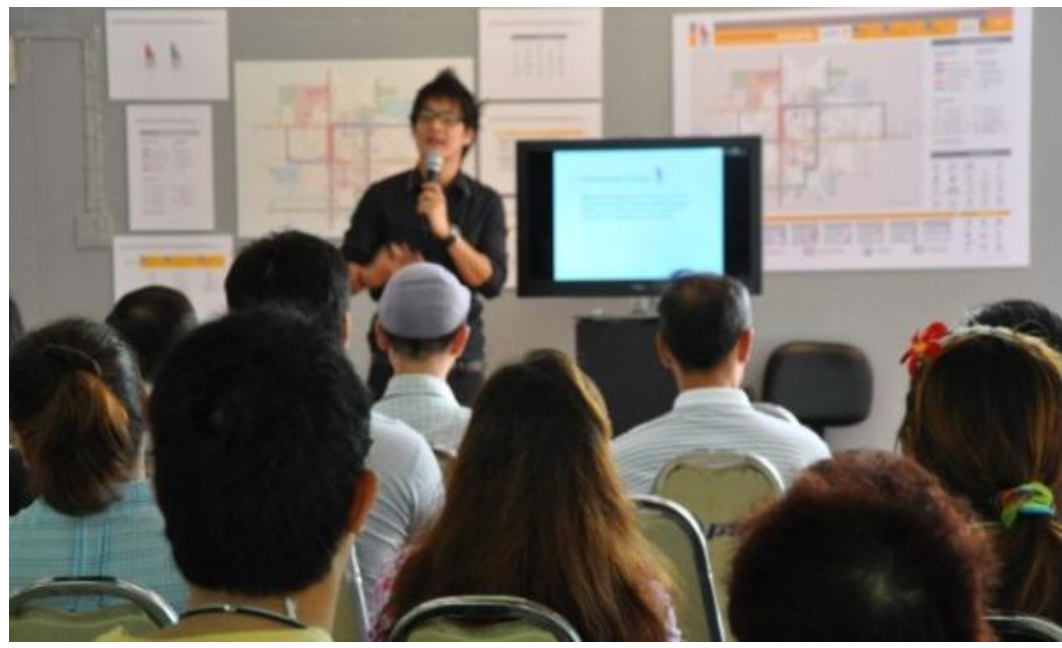

Appendix F. These pictures present the focus group and workshop; during the process of usability test

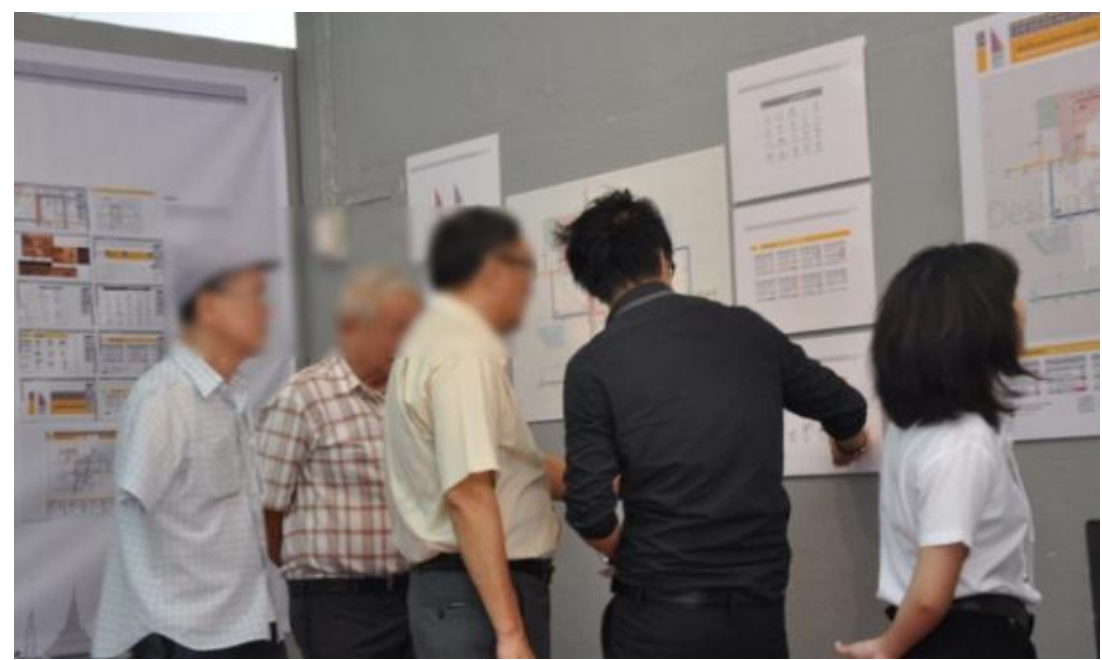

\section{ACKNOWLEDGMENT}

This practical base research has been supported and funded by the Mahasarakham University (MSU) and Auckland University of Technology (AUT). I would like to thank the New Media department who provided the design equipment and laboratory. The author appreciated with my supervisors, participants and Khon Kaen state agencies who gave me with warm welcome, suggestion and participation, during the data collection process. Finally, this project would not have been possible without these people and organizations as above.

\section{REFERENCES}

[1] K. K. Municipal. (2010). Three Years Development Plan of Khon Kaen Municipal: 2010-2012. [Online]. Available: http://www.kkmuni.go.th/plan/plan-53/section-4-1.pdf

[2] NKPCO. (2008). Nongkhai Provincial Cultural Office: History of Nongkhai City. [Online]. Available: http://nongkhaiculture.igetweb.com/index.php?mo=3\&art=220323

[3] T. B. Grandstaff, S. Grandstaff, V. Limpinuntana, and N. Suphanchaimat, "Rainfed revolution in northeast Thailand," Southeast Asian Studies, vol. 46, no. 3, pp. 289-376, 2008.

[4] P. Duk, P. Sinrarat, P. Boonnark, and W. Jiwachaisuk, The Folk Culture: Beliefs 4 ed., Bangkok: Chulalongkorn University Press, 1993.
[5] Library of Treasury Department, The development of culture, history, identity and wisdom of Khon Kaen province, Bangkok: The Fine Arts Department Press, 2000

[6] T. T. Vo, "ASEAN economic community: Perspective from ASEAN's transitional economic," in Roadmap to an ASEAN Economic Community, D. Hew Ed., Singapore: ISEAS Publications, pp. 105-126, 2005.

[7] NESD. (2010a). National Economic and Social Development and Planning. (1980-1986). [Online]. 5. Available: http://www.nesdb.go.th/Default.aspx?tabid=87

[8] R. Banomyong, A. Sopadang, and S. Ramingwong, "Logistics benchmark study of the east west economic corridor," Business Management Quarterly Review, vol. 1, no. 2, pp. 1-13, 2010.

[9] NESD. (2010b). Summary the Tenth National Economic and Social Development Plan (2007-2011). [Online]. Available: http://www.nesdb.go.th/Default.aspx?tabid=139

[10] D. Hew, "Introduction: roadmap to an ASEAN economic community," in Roadmap to an ASEAN Economic Community, D. Hew (Ed.), Singapore: ISEAS Publications, pp. 1-12, 2005.

[11] R. Cervero, "Paradigm shift: From automobility to accessibility planning," Urban Futures Journal, vol. 1, no. 22, pp. 9-19, 1996.

[12] K. Lynch, The Image of the City, Cambridge: The MIT Press, 1960.

[13] J. Allard, "Coping with complexity: Reconfiguring the navigation system for Santiago's new transportation plan,” Information Design Journal, vol. 16, no. 3, pp. 163-177, 2008.

[14] D. Gibson, The Wayfinding Handbook: Information Design for Public Places, New York: Princeton Architectural Press, 2009.

[15] W. Hunt, Designing and Planning Environmental Graphics, New York: Madison Square Press, 1994.

[16] T. Ratanachote and M. Waring, "Using human-centred design to create well transit map recognition in the city: A 'developing country' case 
study,” European Journal of Social Sciences, vol. 43, no. 1, pp. 106-117, 2012.

[17] B. Udom, Sin-Chai Mural Painting, Khon Kaen: Khlangnanatum Press, 2004.

[18] R. Tawanchai, P. Sarun, and N. Thing, Sinchai with Urban Development 2006-Present: By Khon Kaen Municipality, Khon Kaen: khlangnanatum Press, 2006.

[19] R. A. Billington, American's Frontier Heritage, New York: Holt, Rinehart \& Winston, 1974.

[20] J. L. Creighton, Citizens in Community Decisions Making: A Guidebook, Washington DC.: Program for Community Problem Solving, 1994.

[21] E. B.-N.Sanders and U. Dandavate, "Design for experiencing: new tools," in Proc. Symposium Conducted at the Meeting of the First International Conference on Design and Emotion, C. J. Overbeeke and P. Hekkert (Chair), TU Delft, 1999.

[22] H. Sanoff, "Community participation in riverfront development," Co Design, vol. 1, no. 1, pp. 61-78, 2005.

[23] C. Spinuzzi, "The methodology of participatory design,” Applied Research, vol. 52, no. 2, pp. 163-174, 2005.

[24] T. Winogard, Bringing Design to Software, Boston, MA: Addison-Wesley, 1996.

[25] M. J. Muller, "Participatory design: The third space in HCI," in Handbook of HCI, 2 ed., J. Jacko and A. Sears Eds., New Jersey: Erlbaum, pp. 1051-1068, 2007.

[26] F. S. Visser, P. J. Stappers, R. V. D. Lugt, and E. B.-N. Sanders, "Context mapping: experiences from practice," Co Design, vol. 1, no. 2, pp. 119-149, 2005.

[27] F. Kensing and J. Blomberg, "Participatory design: issues and concerns,” Computer Supported Cooperative Work, vol. 7, no. 1, pp. 167-185, 1998.

[28] D. Schuler and A. Namioka, Participatory Design: Principles and Practices, Michigan: Hillsdale: Erlbaum, 1993.

[29] A. J. Fletcher, J. Guthrie, P. Steane, G. Roos, and S. Pike, "Mapping stakeholder perceptions for a tird sector organization," Journal of Intellectual Capital, vol. 4, no. 4, pp. 505-527, 2003.

[30] J. Frooman, "Stakeholder influence strategies," Academy of Management Review, vol. 24, no. 2, pp. 191-205, 1999.

[31] T. Jokela, N. Iivari, J. Matero, and M. Karukka. (2003). The standard of user-centered design and the standard definition of usability: Analyzing ISO13407 against ISO 9241-11. [Online]. Available: http://delivery.acm.org/10.1145/950000/944525/p53-jokela.pdf?key1
$=944525 \& \mathrm{key} 2=1609879921 \& \mathrm{coll}=\mathrm{DL} \& \mathrm{dl}=\mathrm{ACM} \& \mathrm{ip}=156.62 .3 .26 \&$ CFID $=13238164 \&$ CFTOKEN $=42419913$

[32] J. Creswell, Research Design: Qualitative, Quantitative, and Mixed Methods Approaches, Thousand, California: Sage Publications, 2003.

[33] O. R. Holsti, Content Analysis for the Social Sciences and Humanities, Reading: MA: Addison-Wesley, 1969.

[34] P. D. Leedy and J. E. Ormrod, Practical Research: Planning and Design (7th ed.), New Jersey: Prentice-Hall, Inc, 2001.

[35] S. B. Merriam, Case Study in Education: A Qualitative Approach, San Francisco: Jossey-Bass, 1991.

[36] ISO7001, Graphical Symbol-Public Information Symbols, Geneva: International Organisation for Standardisation, 2007.

[37] J. Nielsen, Usability Engineering, San Diego: Academic Press, Inc, 1993.

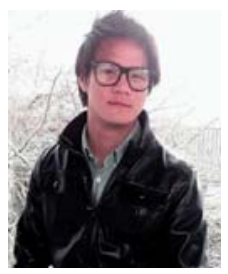

R. Thienmongkol was born in Khon Kaen city, Thailand. The city is in the Northeastern part of Thailand as we called "Isan region". In 2005, he earned the bachelor of fine and applied arts (BFA) in communication design from Bangkok University, Thailand. Then in 2007, he finished his master degree in marketing management from Central Queensland University (CQU), Australia. In 2014, he obtained his $\mathrm{PhD}$ (Communication Design) from Auckland University of Technology (AUT), New Zealand.

At present, his is a lecturer and researcher with academic experience in the areas of; "Graphic Design" for a new media technology and creative industry. He is teaching under/postgraduate courses at the Department of New Media, Faculty of Informatics, MSU Thailand. The field of his research is majoring in graphic design, information architecture, HCD \& UCD, Co-design, participatory design, experimental design, human factors, multi \& creative medias and motion graphic. His design experiences involve with a creative design industry in across countries such Thailand, Australia and New Zealand. His areas deal with, i.e. graphic design, information design, design research/consultant, design branding/marketing research, consumer behavior, corporate design, typography, packaging design, exhibition design, and a guest design lecturer in the higher education. 